\title{
Bacteria, fungi and arthropod pests collected on modern human mummies
}

\begin{abstract}
A survey of opportunistic biocenosis (macro and micro organisms) associated with a rest of human mummy samples was carried out to characterise the biocenosis and to detect the potential of biodeteriogens. The rests of the human modern mummies come from a hypogeic site. Since mummies are relevant from a historic-artistic-scientific point of view, an aspect of this study was the identification and characterization of the biological systems related with biodeterioration of organic matter. In a first step, different sampling methods, according to the taxa, were applied. Technological procedures were combined in order to have an interdisciplinary approach to the conservation actions for testing future restoration protocols. Specimens were collected, identified and characterized by Microscopy (light, SEM, CLSM) and molecular analyses (DNA extraction, in vitro target sequence amplification, sequencing, sequence analysis). The results highlight a rather complex biocenonsis consisting of fungi, cyanobacteria, several insects and other arthropods.
\end{abstract}

Key words: biodeteriogens, biocenosis, conservation biology, hypogeic site.

\section{INTRODUCTION}

In recent years, biomedical technologies have led to a great increase of knowledge concerning the study of human remain collections, as mummies, and their associated materials (Sineo et al., 2008). Both mummies and skeletons can yield a huge amount of biological information. Since they represent cultural assets with relevant historicartistic-scientific interest (Favole, 2003), an aspect of this study is the identification and characterization of the biological systems related with biodeterioration of organic matter. The detection of opportunistic biocenosis and the identification of macro and micro biodeteriogens are essential for an optimal conservation. Biodeterioration involves different biological systems (especially microbial and insect species), representing a relevant problem in conservation of cultural assets (Valentin, 2003a; Valentin, 2003b; Jurado et al., 2008). In this study we integrate the observations of the microbial composition with arthropods affecting the conservation of modern mummies. Assessing the composition of microorganisms and of the fauna communities represents the first step in understanding and controlling colonization and infestation. Fungi, bacteria, cyanobacteria and related microrganisms, can be found on and beneath surfaces of 
cultural assets in indoor and outdoor environments in relation to environmental factors and food sources (Palla et al., 2010). After colonization, microbes can initiate biodeterioration processes or they can continue to live at a low metabolic activity rate, in a biofilm. Moreover, many insects and other animals can be found in association with human mummified bodies or conservation environments (Smith, 1986; Sukontason et $a l .$, 2006). For this reason we focus the attention on bacteria, fungi and entomofauna associated with the mummies inhabiting catacombs or other hypogeic sites. In the literature, many studies were conducted on the sequence of arthropods that colonize exposed corpses (Bourel et al., 2004). However, some defined environmental conditions such as hypogeic site have been poorly studied. Catacombs are particular hypogean environments which have a partial connection with the outdoor and the soil that may influence the characteristics of the biocenosis (Saarela et al., 2004). Our goal is to investigate the biocenosis associated with mummies and indicate the potential biodeteriogens currently or previously present.

\section{MATERIALS AND METHODS}

\section{Sampling}

We pay attention on micro-organisms and macro-organisms found in hypogean environments, colonizing both mummy surfaces and aerosol. Microbial biofilms were sampled by sterilized swabs while arthropod rests were collected by a rigger brush.

\section{Identification}

Identification was performed using different procedures according to the different taxa:

- Light Microscopy: samples were prepared for observation under DLMB Leica (Wetzlar, D, Magnitude 400-1200 X).

- Scanning Electron Microscopy (SEM): samples were coated with approximately 13 nanometers of gold by Agar-Auto-Spotter-Coater (B7341) and observed under high vacuum Leica Cambridge-Leo 420.

- Confocal Laser Scanning Microscopy (CLSM): since some bacterial colonies, especially cyanobacteria, are autofluorescent we performed the observations by CLSM (Olympus FV 300) equipped with argon (488 nm) and helium-neon (543 nm) lasers, together with calibrated emission filters.

- Molecular DNA analysis: total microbial DNA, directly extracted from surface and aerosol samples, was used as template in PCR reactions. The target DNA sequences were localised both on specific 18S (fungi) or 16S (bacteria) RNA locus and on 18S$26 \mathrm{~S}$ (fungi) or 16S-23S (bacteria) intergenic transcribed spacer (ITS). The sequence of amplified fragments were determined and analysed to elicit the prevalent microbial species in biofilm and bio-aerosol. Comparison between fragment sequences and bacterial genomic DNA deposited in Genebank, was carried out by dedicated software (BLAST, ClustalW, TreeW). 


\section{RESULTS AND DISCUSSION}

Analysis of mummy and debris of the bonds showed different evidences of deterioration: huge microbiological colonization (bacteria, fungi), tiny holes in the bonds and brownish dusts (indicators of insect activity). Carcasses and fecal pellets of the insects were mixed with dusts and debris. The presence of insects (Fig. 1, A) and microorganism colonization can indicate also the environmental conditions of the process and the estate of the mummy. Particularly, we focused on samples from crania that showed a quite complex biocenosis characterised by the presence of several species of insects. Levinson \& Levinson (1994) reported that a complicate biocenosis was recorded in the ancient Egypt tombs and mummies, but some of insects were associated with the food
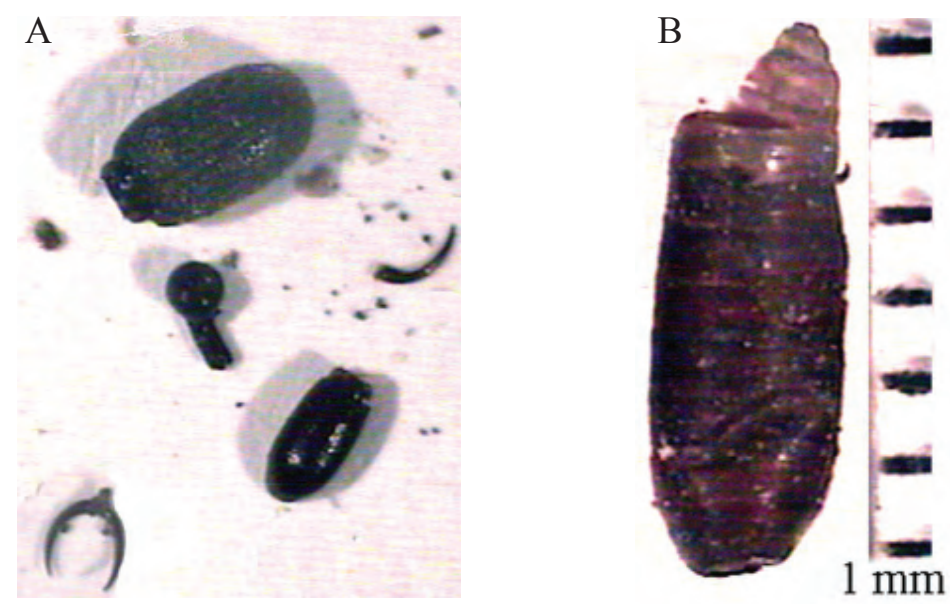

Fig. 1 - (A) Rests of insects found in the crania debris of human mummy. (B) Puparium of Phoridae specimen with the typical respiratory horns.

present in the tombs.

In our study we recorded many taxa of insects (at least six were non accidental species). Parts of adult arthropods (head, tibia, claw and pre-claw, thorax, femur) have been found, mainly belonging to Coleoptera Curculionidae, Cleridae, Latridiidae and Ptinidae. Also a golden brown chela of pseudoscorpion (Pseudoscorpionida) was recorded. Pseudoscorpions are found under rocks, or in caves, and use their pinchers to prey upon micro-arthropods.

The arthropods collected are reported in Tab. 1. Different mites and dipteran puparia were also recorded (Fig. 1, B). Most of the puparia were empty: 4 entire and many rests. Since anterior rupture, due to adult emergence, was circular they belong to Diptera Cyclorrhapha. A number of characters helped the identification: the overall structure of puparia is ovoidal, two big respiratory horns, with several holes and a trabecolar struc- 


\begin{tabular}{|c|c|c|c|c|}
\hline Class & Order & Families & $\mathbf{N}$ & \\
\hline \multirow[t]{2}{*}{ Arachnida } & Acarina & Acaridae & 1 & many rests (to be determined) \\
\hline & Pseudoscorpionida & Cheliferidae & 1 & 1 chela \\
\hline \multirow[t]{5}{*}{ Insecta } & Coleoptera & Cleridae & 1 & $\begin{array}{c}\text { parts of the head plus part of } \\
\text { exoskeleton }\end{array}$ \\
\hline & & Curculionidae & 4 & $\begin{array}{l}3 \text { entire heads (of } 2 \text { different } \\
\text { species) plus many rests }\end{array}$ \\
\hline & & Latridiidae & 1 & head plus part of exoskeleton \\
\hline & & Ptinidae & 1 & $\begin{array}{l}\text { head plus other part of } \\
\text { exoskeleton }\end{array}$ \\
\hline & Diptera & Phoridae & 4 & many rests \\
\hline
\end{tabular}

Tab. 1 - Arthropods collected in 2.5 grams of human mummy cranial debris. N: certain number of individuals.

ture are present on the dorsum, at the end of $5^{\text {th }}$ segment. Altogether, these morphological features allowed us to identify these specimens as belonging to the Phoridae, the specific identification is possible only by the adults (Liu \& Greenberg, 1989), as taxonomy is based upon the female ovipositor. Nevertheless, phorid puparia morphology is rather uniform, so examination under SEM (in progress) could reveal details useful for identification at specie level (Sukontason et al., 2006). A complete identification could be important to define their role in mummy conservation.

Phorids are known as coffin flies, because they live in human corpses with such tenacity that they can even continue their life cycle within the wood of coffins (Smith, 1986). Larvae live in a numerous variety of locations such as dung, fungi, and decaying organic matter. They can be saprophagous, coprophagous, mycophagous, or parasitic. In nature, they are typically associated with dead animals and heavily decaying matter. Their reproductive potential is tremendous.

Regarding microorganisms we found bacteria. The most abundant species were cyanobacteria (Fig. 2a, b) revealed by molecular analysis through CLSM, and fungi (Fig. 3). Considering the high number of specimens collected and the kind of taxa they belong to, we can conclude that the organisms found good conditions for their propagation and rapid build-up of dense pest populations. In fact, we can suppose that a complex biocenosis with different trophic levels (Fig. 4) is present in the rest of this mummified body. However, bioceonosis can be associated to: $i$ ) the time of the dead to the body (what does this mean?); ii) different processes of mummification; iii) the decomposition lev- 
el $(?) ; i v)$ the eventual parasitism before dead; $v$ ) the environmental location of the mummy. Thus the findings of dead insects and microbial colonization does not allow to date the time of infestation. Nevertheless the presence of living organisms such as cyanobacteria (Fig. 2a, b) highlights that colonization is going on.

The study of insects and other animals associated to mummies or inhabiting catacombs is important also in relation to fungi. Recently Jurado et al. (2008) conclude that when

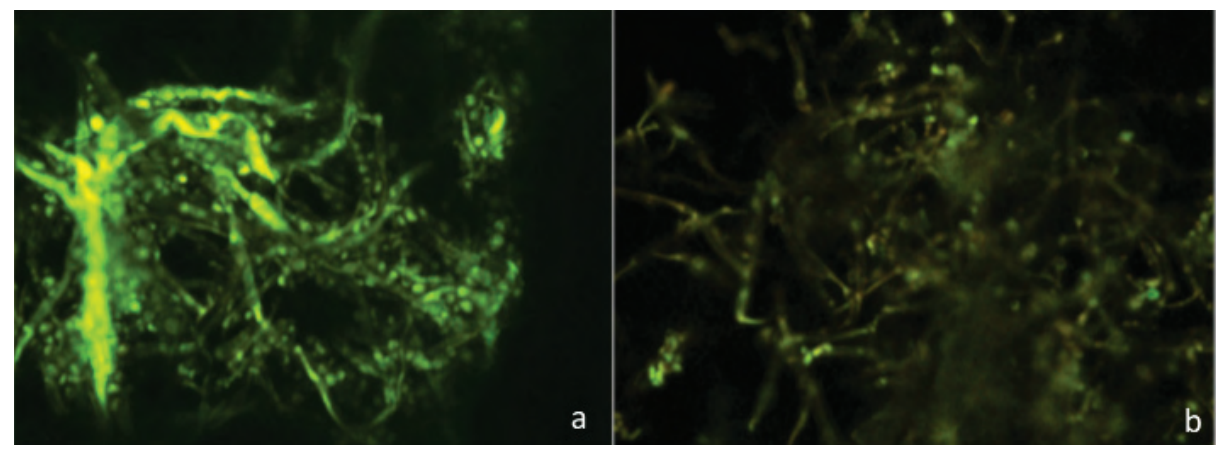

Fig. 2 - Photographs $(\mathrm{a}, \mathrm{b})$ of Bacteria and Cyanobacteria at Confocal Laser Scanning Microscopy.

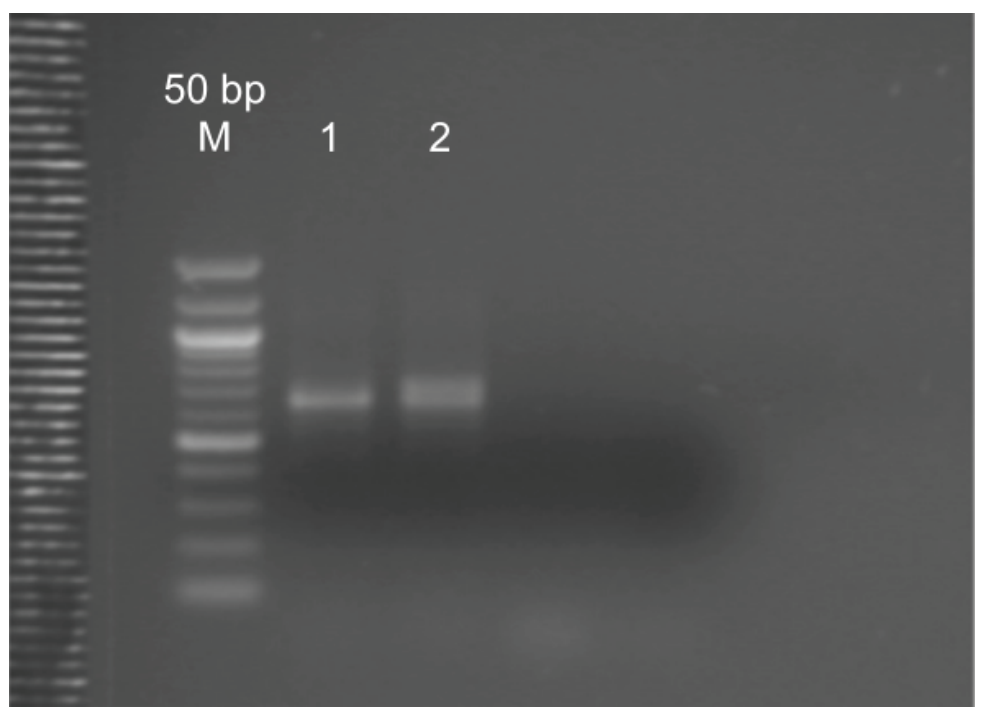

Fig. 3 - PCR amplified DNA fragments analysed by $2 \%$ agarose gel elctrophoresis. Amplification reactions were performed by using ITS (fungal specific) primers. 
investigating fungal colonisation in cultural properties a carefully studies on the arthropods is needed in order to know fungal dispersion patterns and propose countermeasures for the protection of cultural sites. The authors also recorded entomopathogenic

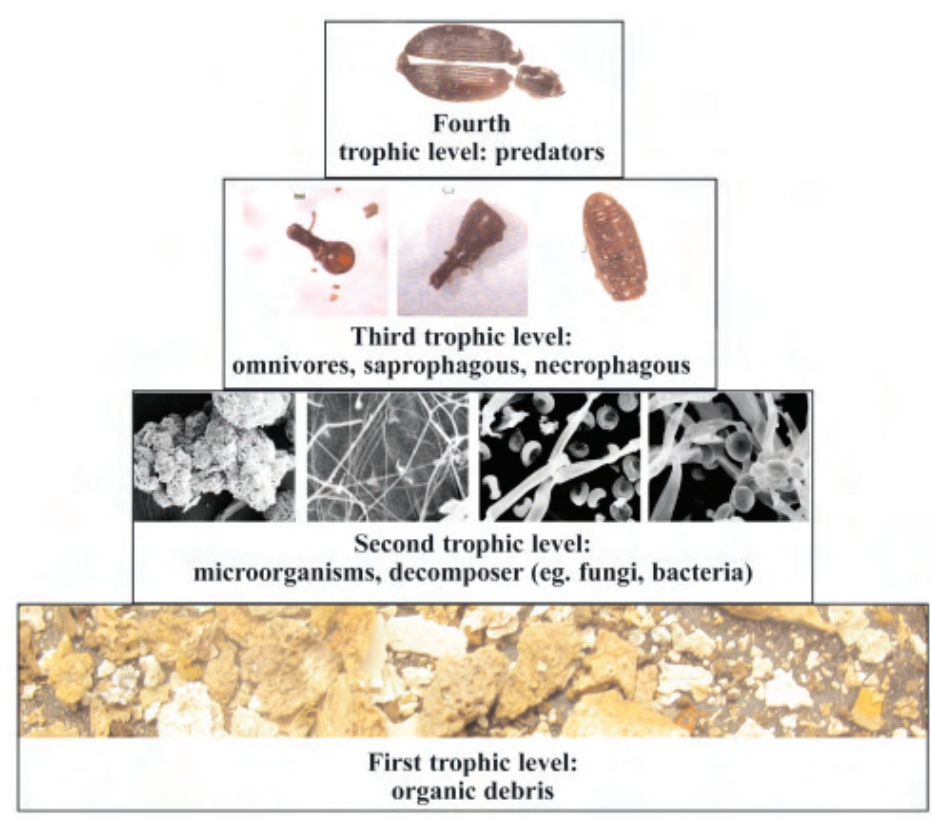

Fig. 4 - Trophic web recorded in the Human Modern Mummies.
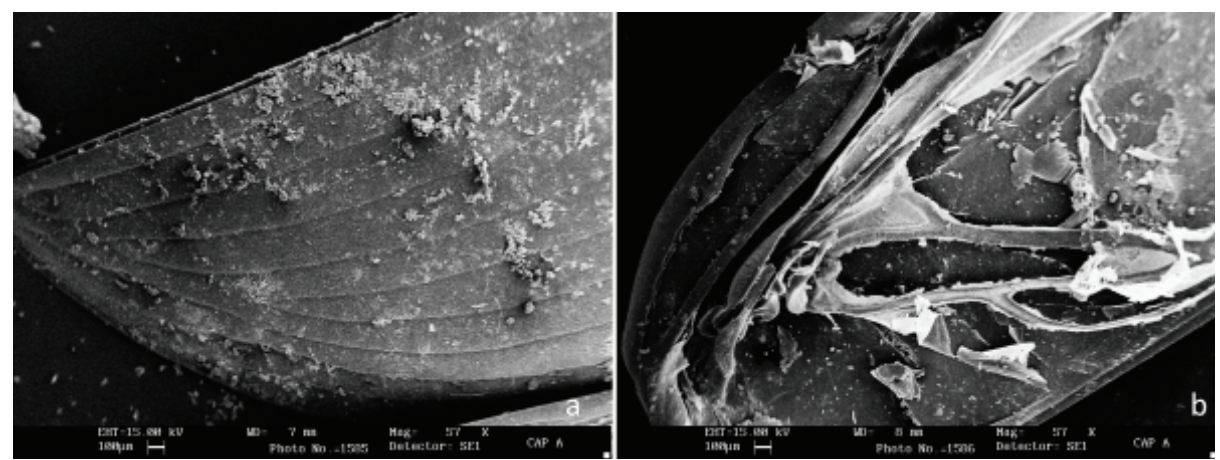

Fig. 5 - Fungi and Bacteria on upper (a) and inner (b) elytra surfaces of a coleopteran specie collected in the human mummy cranial debris, photographed by Scanning Electron Microscopy Leica Cambridge-Leo 420. In b it is possible to notice the venations of the metathoracic wings. 
fungi on mural paintings and in catacombs that could be useful for the control of insect pests. In this study we also report several bacteria and fungi associated to the insect rests (Fig. 5a, b).

\section{CONCLUSIONS}

Concerning microorganisms, as CLSM observations were consistent with PCR results, we conclude that the combination of these approaches improved our understanding of microbial communities thriving on cultural assets, which is essential for the development of conservation and/or restoration strategies. Moreover, using molecular techniques, the analyses are faster; as they are performed with microscopic amount of sample and increased accuracy.

Further studies are necessary to identify the biocoenosis present in the catacombs, possibly using different kind of traps, and to understand their relationships and their role in degradation processes.

\section{ACKNOWLEDGEMENTS}

We would like to express our gratitude to Father Calogero Peri, for granting us permission to collect mummy samples. A special thank is due to C. Di Liberto for SEM and G. Morici for CLSM analyses.

\section{REFERENCES}

Bourel B., Tournel G., Hédouin V., Gosset D., 2004 - Entomofauna of buried bodies in northern France. International Journal of Legal Medicine, $118: 215-220$.

Favole A., 2003 - Resti di umanità. Vita sociale del corpo dopo la morte. Roma-Bari, Ed. Editori Laterza: 1-216.

Jurado V., Sanchez-Moral S., Saiz-Jimenez C., 2008 - Entomogenous fungi and the conservation of the cultural heritage: A review, 62 (4): 325-330.

LeVInSON H., LeVInSON A., 1994 - Origin of grain storage and insect species consuming desiccated food. Journal of Pest Science, 67 (3): 47-60.

Liu D., Greenberg B., 1989 - Immature stage of some flies of forensic importance. Annals of Entomological Society of America, 82: 80-93.

Palla F., Billeci N., Mancuso F.P., Pellegrino L., 2010 - Microscopy and molecular biology techniques to study biocenosis diversity in semi-confined environment. Conservation Science in Cultural Heritage, 10: 185-194.

Saarela M., Alakomi H.L., Suinko M.L., Maunuksela L., Raaska L., Mattila-Sandholm T., 2004 - Heterotrophic microorganisms in air and biofilm samples from Roman catacombs, with special emphasis on actinobacteria and fungi. Intern. Biodeter. \& Biodeg., 54: 27-37.

Sineo L., Manachini B., Carotenuto G., Piombino-Mascali D., Zink A.R., Palla F., 2008 -The Palermo Capuchin Catacombs Project: a Multidisciplinary Approach to the Study of a Modern Mummy Collection (ca 1600-1900). Conservation Science in Cultural Heritage, 8: 155165. 
Sмiтh K.G.V., 1986 - A manual of forensic entomology. Cornell University Press, Ithaca, NY.

Sukontason K.L., Boonsriwong W., Siriwattanarungsee S., Piangjai S., 2006 - Morphology of puparia of Megaselia scalaris (Diptera: Phoridae), a fly species of medical and forensic importance. Parasitology Research, 98: 268-272.

VALENTIN N., 2003a - Insect infestation in museum collections: organic materials. In: Molecular Biology \& Cultural Heritage. Ed. C. Saiz-Jmenez, Balkema, Netherland: 225-230.

VALENTIN N., 2003b - Microbial contamination in museum collections: organic materials. In: Molecular Biology \& Cultural Heritage - Ed. C. Saiz-Jmenez, Balkema, Netherland: 85-91.

Barbara Manachini, Department of Environmental Biology and Biodiversity, University of Palermo, via Archirafi, 38- 90123 Palermo, Italy.

E-mail: barbara.manachini@unipa.it 